\title{
Hotel Profiles Based on Environmental Management Practices: Evidence from a Study at an Alpine Destination
}

\author{
Federica Buffa ${ }^{1, * \mathbb{C}}$, Mariangela Franch ${ }^{1}$, Umberto Martini ${ }^{1}$ and Alessio Tamanini ${ }^{1,2}$ \\ 1 Department of Economics and Management, University of Trento, Via Inama 5, 38122 Trento, Italy; \\ mariangela.franch@unitn.it (M.F.); umberto.martini@unitn.it (U.M.); alessio.tamanini90@gmail.com (A.T.) \\ 2 Statistical Office of Province of Trento (ISPAT), Via Zambra 42, 38122 Trento, Italy \\ * Correspondence: federica.buffa@unitn.it; Tel.: +39-0461-282146
}

Received: 30 October 2018; Accepted: 27 November 2018; Published: 1 December 2018

\begin{abstract}
This paper analyzes the investment in environmental management practices (EMPs) adopted by hotels within a community destination. The aim is twofold: (a) to understand whether hotels have changed their EMPs in the last ten years and, if so, how; (b) to analyze the link between hotels' environmental commitment and propensity of collaboration among local stakeholders. The research, carried out in 2015, involved all the hotels $(N=1.514)$ of Trentino, a community destination in the Italian Alps, through a CAWI survey (redemption rate $88.9 \%$ ). The data analysis followed two steps: (1) frequency analysis to identify the EMPs adopted by hotels and to compare the data with the survey conducted in 2005; (2) multiple correspondence analysis and hierarchical ascendant cluster analysis to identify hotel profiles with different levels of environmental commitment. The results revealed new and original aspects of the propensities of hotels to invest in EMPs and identified three different environmental hotel profiles: not eco-friendly, proactive, and reactive. Proactive and reactive hotels have a greater propensity to invest in EMPs and to collaborate with the Destination Management Organisation and with other hotels. The research contributes to the scientific debate on EMP adoption and the extent to which stakeholder power and pressure influence the environmental sustainability strategies of hotels.
\end{abstract}

Keywords: environmental management practices; environmental commitment; environmental hotel profiles

\section{Introduction}

The question of sustainability and the quest for the balance between the three pillars upon which it rests $[1,2]$ have drawn increased attention worldwide, gradually influencing the development of all economic sectors, including tourism [3]. A growing awareness of the positive relationship between tourism, well-being, and economic development at the territorial level $[4,5]$ has been encouraging the academic community to seek new developmental models [6-11]. From a managerial perspective, combining the principles of sustainability with those of business management prompts reflection on the adequacy of traditional business models and on the medium- and long-term environmental and social (as well as economic) impacts of the tourism industry. The strategies and operational practices adopted by tourism enterprises are of particular relevance.

The tourism sector is characterized by the presence of a multiplicity of firms which largely define the offer of a particular territory, through their services and products. Of these, the hospitality sector is a key stone of the system [12-14], and it is these firms that-to date-the majority of studies have examined, focusing particularly on what are described by the international literature as environmental 
management practices (EMPs) $[15,16]$. From these studies, it is clear that the adoption of EMPs does not imply that a firm loses focus on its economic aims and the pursuit of profit-the latter objectives, indeed, go hand in hand with environmentally sustainable goals.

The adoption of EMPs assumes particular significance within community destinations, i.e., multi-stakeholder territories in which resources and activities are spread among numerous public and private actors, including the local community [17-20]. In these destinations, the territory itself, with its natural resources, is what makes the tourist offer unique. The integration of the tourism offer depends on the collaboration among actors. To this end, on one hand, the attention to environmental practices is vital to preserve the beauty and attractiveness of the destinations; on the other hand, the involvement of local actors in collaborative relationships and partnerships are essential for destination competitiveness.

In this paper, we discuss the choices made by hotels in EMPs. The aim is twofold: (1) to understand whether hotels have changed their EMPs and, if so, how; (2) to analyze the link between hotels' environmental commitment and propensity of collaboration among local stakeholders.

The research was carried out in Trentino (Italy) administering a questionnaire to 1514 hotels (all local hotels), which had a response rate of approximately $90 \%$. Trentino is a typical community destination, where tourism is key to local development and hotels are a crucial element of the tourism sector. In addition, the local statistics office (Ispat, www.statistica.provincia.tn.it/) enabled us to access the database of all Trentino hotels that, every ten years, is updated thorough a census. This also allowed us to examine how hotels' environmental choices have evolved over time.

The research profiles hotels on the basis of their environmental commitment, i.e., the EMPs that have been adopted within their structures. Having identified three profiles, we analyzed whether hotels' decisions to invest in EMPs were motivated principally by market logic or arose from manager awareness and if different levels of collaboration with key players (i.e., DMO and other hotels) emerged.

The paper is divided into five sections: in the next section, the most important literature on EMPs in hotels is discussed; in the third section, the methodology is described; in the fourth, the main findings are shown. The last section includes conclusions and suggestions for further research.

\section{Literature Review}

All recent trends in international tourism agree on the need to make sustainability a core value, and on the implications that this focus has on both territorial and business management policies and approaches [21-23]. Sustainability is seen as a precondition for destination competitiveness [24,25], and, in developing their offers and services, managers have to adopt strategies that not only preserve and valorize the local environment but also maintain their territory's social equilibrium [26-28].

While the individual awareness of hotels is clearly vital, the role of local public actors should not be minimized. Public (state, regional, municipal) involvement in tourism has a long history [29-33]. Indeed, a destination's strategies must adopt long-term perspectives if tourist flows-with their considerable impacts on both natural and socio-cultural capital-are to be properly managed [4]: tourism management must become an integral part of territorial planning processes and be subject to legislation that ensures the control of its (positive and negative) effects [33-36]. The goal of sustainability must therefore be pursued through a specific tourism policy, since effective governance is a key requirement for the successful implementation of any sustainable tourism model [37,38].

Within community destinations in particular, the firms that opt for sustainable strategies do not merely benefit themselves but also contribute to the protection and valorization of their territory, which is, in turn, one of the main pull factors for the overall tourism offer of the destination. The entire local system is thus positively impacted when hotels adopt more sustainable business models.

The hotel sector tends to have a particularly heavy impact on the environment, although its effects vary in frequency and intensity depending on the phase being assessed-during infrastructure construction, for example, activity is more intense but is short-term, while the routine activities involved in the provision of goods and services for guests are ongoing but are less invasive [39]. The latter activities involve the consumption of energy, water, food, paper, etc., inevitably leading 
to the consumption of non-renewable raw materials and increased emissions [40]. Seen in isolation, any one of these activities may not appear to have a particularly large impact, but-above all when considered at the global level — the hotel industry is, in fact, both resource-intensive and a significant polluter [41,42].

In light of the above, analysis of the environmental practices of hotels is currently of considerable interest to the scientific community, as there is still much to be learnt about the EMPs available, particularly to the smallest firms (small and medium hotel enterprises-SMHEs) [43]. Most of our evidence comes from studies on big hotels, or those belonging to chains; see, for example, [44-47]. These studies have contributed to the debate on the various methods, time-frames, and investments open to big firms and SMHEs adopting EMPs. It is, of course, not impossible for SMHEs to adopt EMPs, but to do so they have to make the kinds of strategic and organizational choices that can enable them to overcome the limitations all too typical of small firms [48]. Such choices require the adoption of a new business model, directed towards the achievement not only of competitive advantage for the business itself but also for the entire territory. Porter and Kramer [49] use the term "win-win business model" and [50] describe approaches open to sustainability as being "win-win for firm and system." Other studies have demonstrated that SMHEs that deploy EMPs are rewarded by improved performance, environmental, economic [46,51], and competitive [52,53].

A firm's decision to adopt an EMP may be influenced by its stakeholders [54]. Céspedes-Lorente et al. [55] have shown that a hotel firm's deployment of EMPs is often subject to stakeholder power and the stakeholders' various perceptions of environmental issues and how these can be addressed by the hotel. Ayuso [56] and other authors [57,58] discuss the phenomenon of stakeholder pressure, highlighting the extent to which external stakeholders can influence the strategic choices of hotel firms with regard to environmental sustainability.

This overview of the literature indicates the timeliness of our research, given the knowledge gap that still exists around EMPs and their deployment, particularly by SMHEs. The research carried out on the Trentino hotels is especially relevant to the scientific debate because the majority of hotels in the area are SMHEs family run. Within this context, moreover, the analysis of whether or not some key local stakeholders can be considered to have exerted the stakeholder power and stakeholder pressure described in the literature has proven interesting. This was also our motivation for investigating if levels of investment in the environment are uniform throughout the territory, or if differences emerge, attributable to the influence of the DMOs on the choices made by hotels.

\section{Methodology}

\subsection{Population and Focus of Analysis}

The data collected by Ispat through a CAWI survey carried out in 2015 have enabled us to build the first (ever) environmental commitment profiles of hotels. The survey covered all (1514) hotels, with a response rate of $88.9 \%$, giving us an analysis base of 1347 . Most of the hotels have three stars and the average bed number is 61 . The great majority are independent (only $3.3 \%$ are members of a chain) and family run ( $87 \%$ are owner-managed, either alone or with the help of family members).

The questionnaire administered to the hotels was divided into two main sections:

- the first covered data related to the adoption of specific EMPs;

- the second enquired into the interviewees' motives for embarking upon environmentally sustainable projects.

The questions in the first section concerned specific environmentally friendly investments in energy and water conservation measures, incentives for green mobility, and the use of eco-friendly products and organic food. Three response options were given: an indication that a measure had been adopted, had not been adopted, or was intended to be adopted. The third option enabled us to capture hotels' declared future intentions, key to the creation of the firms' profiles through a cluster analysis (see infra). The EMPs investigated and the response options are illustrated in Table 1. 
Table 1. Environmental management practices (EMPs) investigated in the hotels of Trentino.

\begin{tabular}{lc}
\hline \multicolumn{1}{c}{ Emps } & Response Option \\
\hline $\begin{array}{l}\text { Installation of solar water/photovoltaic panels } \\
\text { Thermal insulation }\end{array}$ & \\
Light timers & \\
Dual flush WCs & $0=$ measure not adopted \\
Reuse of white water & $1=$ measure intended \\
Towel change on request only & $2=$ measure adopted \\
Rainwater harvesting (for use in watering plants) & \\
Use of phosphate free and/or highly biodegradable detergents & \\
Free bike hire & \\
Subsidised public transport/travel card schemes &
\end{tabular}

Source: authors' elaboration.

We focused on the above EMPs in order to include both those practices that require heavy investments on the part of businesses-and that an SMHE might not be able to afford without assistance-and those that are much cheaper and therefore within the budgets of even the smallest firms (such as dual flush WCs, eco-friendly detergents, and clean towel provision on request). The latter measures can help to lessen a hotel's environmental impact on its immediate environment by reducing emissions and water and energy use.

With regard to energy conservation, we investigated practices which are attracting growing interest on the part of both private individuals and businesses (as demonstrated by the increased investments in photovoltaics evidenced in the most recent (2017) Istat (Italian National Institute of Statistics) report [59]), and it is therefore not surprising that hotel businesses, too, are adopting/considering them. The exposition of these data enables us not only to analyze the energy conservation investments made or planned by businesses but also to understand how such investment levels compared with those revealed in the last (2005) Ispat survey.

The aspects of water conservation investigated, as indicated in Table 1, are the installation of dual flush WCs (which range from an average of 10 (full flush) to $3 \mathrm{~L}$ (partial flush)), white water recycling systems, and rainfed irrigation systems. The importance of this analysis is thrown into sharp relief by the data published by the ENEA (the national agency for new technologies, energy and sustainable economic development-www.enea.it/en), revealing the extremely high levels of water consumption in Italian hotels (between $200 \mathrm{~L}$ per day in the low season and $600 \mathrm{~L}$ in the high season), particularly in relation to the use of showers and wash basins (70-120 L), WCs (30-70 L), kitchen/ cooking (20-40 L), washing (both on and off site), and irrigation. It is estimated that $80 \mathrm{~L}$ of water per guest per day can be saved through the installation of devices for the conservation and recycling of water and nutrients and through the separation of white, grey and black water.

The enthusiasm for towel changing only at the client's request follows the same logic; now a common practice in hotels, its analysis reveals not only the choices made by hotels but also client attitudes, and whether they are interested in environmental issues and are thus ready to collaborate with the eco-friendly choices made by their hotel.

In addition to the analysis of practices principally linked to reduced environmental impact, such as the use of phosphate free/biodegradable detergents, we investigated the promotion of practices linked to mobility: the most prevalent of these were free bike hire at a significant number of hotels, and incentives to use the local public transport network.

In order to complete the analysis, two questions about the hotel kitchens' use and offer of organic products and the obtaining of certification were included in this first section of the questionnaire. The question on certification reveals whether the hotels have already obtained, or intend to apply for, a certification of quality management (ISO 9001) or of environmental management, or an environmental label (i.e., ISO 14001, Emas, Ecolabel). 
The questions in the second part of the questionnaire focus on why hotels invest in EMPs. The motivations examined included both economic and competitiveness, and ethical and cultural, factors. The interviewees were asked to score the strength of their agreement with each motivation on a Likert scale with four positions. Table 2 lists the hotels' investment motivations and the response options offered.

Table 2. Motivations for investment in EMPs among hotels.

\begin{tabular}{ll}
\hline \multicolumn{1}{c}{ Motivations } & \multicolumn{1}{c}{ Response Options } \\
\hline Because clients appreciate them & $1=$ strongly disagree \\
Ethical & $2=$ somewhat disagree \\
Cost-saving & $3=$ agree \\
Possible competitive advantage & $4=$ strongly agree \\
Because it's imperative if I want to remain in the market & \\
Important in Trentino in order to maintain a culture firmly rooted & \\
in and in symbiosis with the territory & \\
\hline
\end{tabular}

Source: authors' elaboration.

\subsection{Data Analysis}

The data analysis was carried out on two levels. First, we analyzed the frequency and percentage of responses from the hotels referring to the EMPs they had adopted. These data were compared with the results from the previous (2005) Ispat survey in order to establish whether and how investments in environmental sustainability had changed. As we go on to demonstrate, it was not possible to compare all the EMPs adopted because, over the 10 intervening years, it was considered opportune to introduce some modifications, both with regard to the EMPs analyzed and to the factors driving firms' investments. For example, in 2015, the adoption of magnetic cards for electricity is included, while in 2005 this practice was not taken into consideration. Hotels' motivations, meanwhile, are analyzed in greater detail in the 2015 survey, with a distinction being made between investments already made and those intended, thereby allowing us to identify more precisely the propensity of hotel firms to adopt "green" measures. These changes have resulted in somewhat different sets of questions and therefore not all of the data are comparable.

The second level of analysis was conducted in order to build the profiles of the SMHEs on the basis of their environmental commitment. To do this, the future intentions of the hotels had to be analyzed, taking into consideration not only already adopted practices but also those about to be adopted. The cluster analysis was made using the 10 variables linked to the adoption of EMPs (see Table 1), plus an 11th, which measured the use of organic produce in hotel kitchens. All 11 variables are qualitative. The profiles were created in two steps: first, a multiple correspondence analysis (MCA) and, only after that, a cluster analysis: the nature of the variables did not permit a cluster analysis of the raw data.

The aim of the MCA was to reduce the number of variables and reposition the data within a new Cartesian plane, identifying two new main axes; the cluster analysis was carried out in order to profile the firms on the basis of their (past and future) environmental investments, motivations, and links with some key players in the territory. More specifically,

- The MCA resulted in an output in which the two new axes identified explain $87.72 \%$ of the total inertia. The graphic output produced by the XLstat 2017 software (see Figure 1) reveals that the horizontal axis measures the strength of future intention to invest in EMPs, while the vertical axis reveals the existence (or absence, with a value of 0 ) of EMPs within a hotel. A hotel's position on the graph thus depends on both previous/current and intended investments.

- The identification of the two new main axes upon which to place the variables and observations allowed us to conduct a hierarchical ascendant cluster analysis and-using quantitative data-to 
use a Euclidean distance matrix. The cluster analysis revealed three groups, differentiated according to levels of investment in EMPs and future intentions in this regard (see Section 4.2).

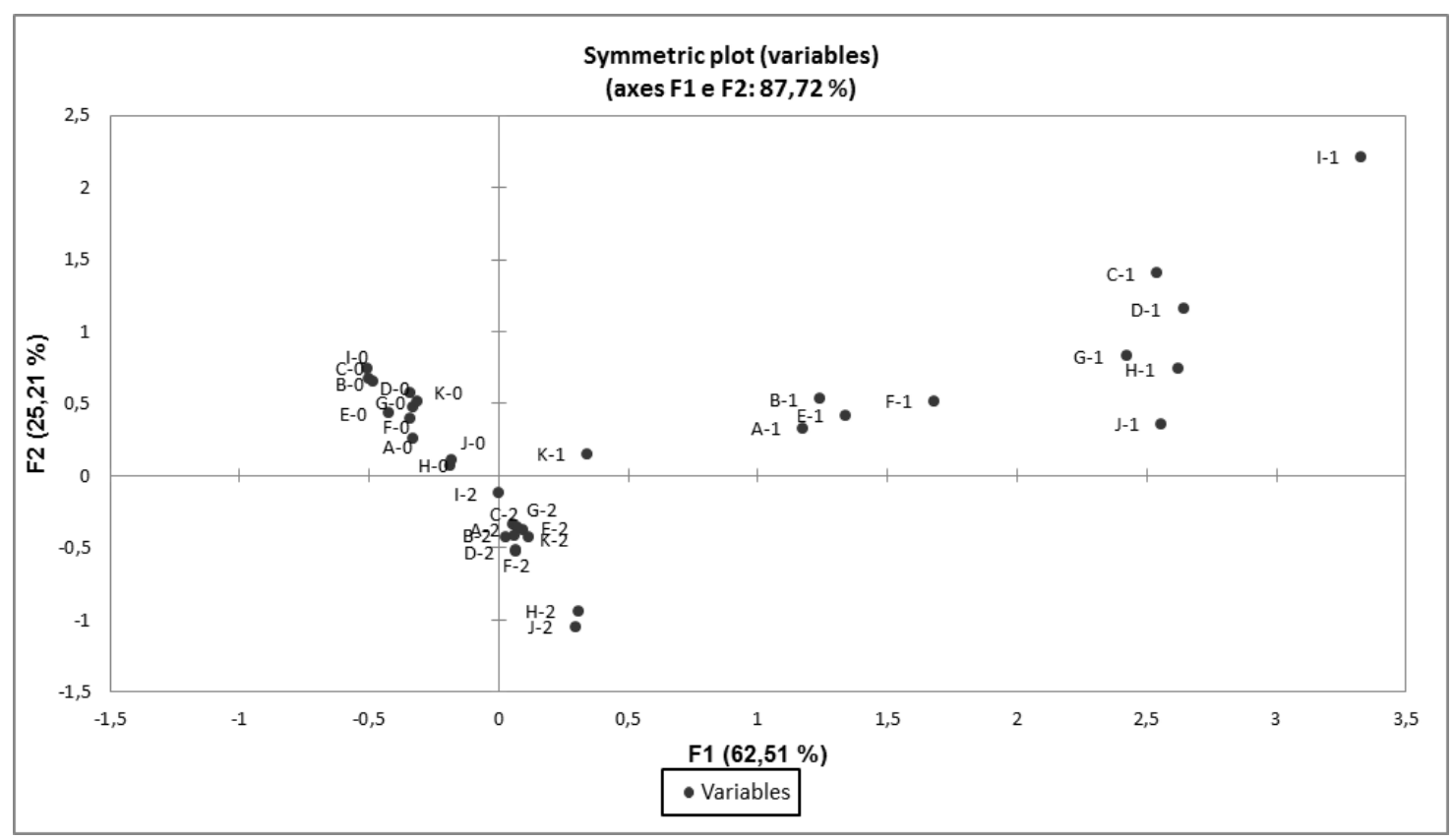

Figure 1. Multiple correspondence analysis output. Note: the term "variable" refers to the 11 EMPs analyzed in conjunction (see the legend below) with the three response options $(0=$ measure not adopted; 1 = measure intended; 2 = measure adopted). $\mathrm{A}=$ installation of solar water $/$ photovoltaic panels; $\mathrm{B}=$ thermal insulation; $\mathrm{C}=$ light timers; $\mathrm{D}=$ dual flush WCs; $\mathrm{E}=$ use of phosphate free and/or highly biodegradable detergents; $F$ = free bike hire; $\mathrm{G}$ = subsidised public transport/travel card schemes; $\mathrm{H}$ = reuse of white water; $\mathrm{I}=$ towel change on request only; $\mathrm{J}$ = rainwater harvesting (for use in watering plants); $\mathrm{K}=$ use of biological products. Source: authors' elaboration.

The cluster analysis produced the hotels' profiles and enabled us to analyze, for each profile, the motivations driving investment in EMPs and whether the DMOs had influenced firms' strategic choices.

\section{Research Findings}

\subsection{EMPs Adopted by Hotels}

The descriptive analysis reveals the EMPs adopted by the hotels and how investments have changed over the course of the decade between 2005 and 2015. As already noted, it was not possible to carry out a longitudinal analysis of all practices. Nevertheless, it is possible to capture the differences between the investments in specific EMPs by referring to the response option "not adopted". This analysis reveals the growth in hotels' investments in EMPs (see Table 3).

The most obvious increases have been in energy conservation measures, with an increase in solar water panels from $22.4 \%$ and in photovoltaics from 6\% (in 2005) to $41.7 \%$ in 2015 (52.1\% if intended investment is included). The installation of thermal insulation has also seen a significant increase: from $44 \%$ to $59.3 \%$ ( $70 \%$ if intended investment is included).

Light timers are the most prevalent measure, found in $70.4 \%$ of hotels. These devices result in significant reductions in energy consumption due to their limiting the amount that the time stairs, corridor, and walkway lights remain on. Magnetic cards to control power supply in rooms, however, have only been adopted by $33 \%$ of hotels. 
Table 3. Adoption of EMPs by hotels (2005 and 2015).

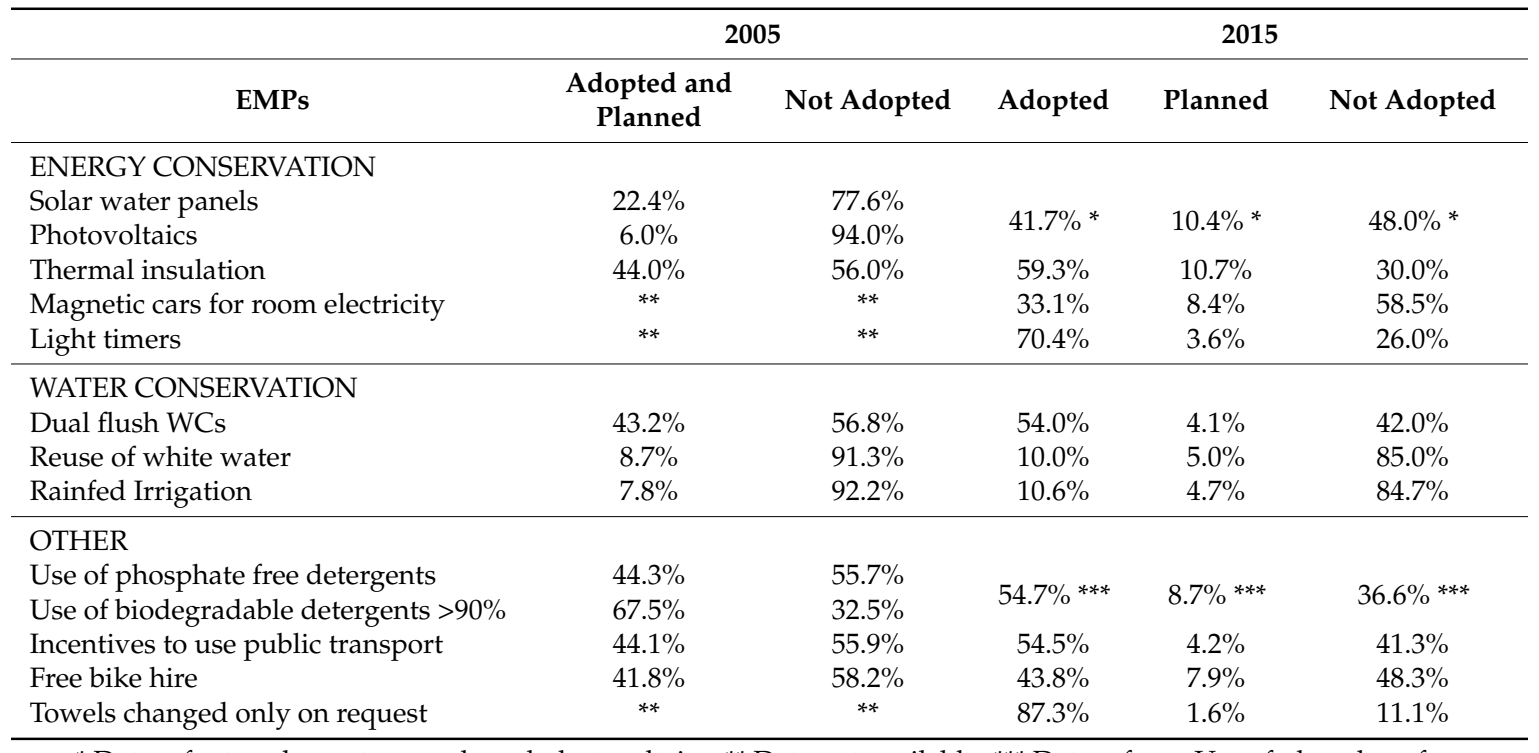

* Data refer to solar water panels and photovoltaics. ${ }^{* *}$ Data not available. ${ }^{* * *}$ Data refer to Use of phosphate free detergents and Use of biodegradable detergents $>90 \%$. Source: ISPAT (2006) [60] and authors' elaboration.

Of the water conservation measures surveyed, only dual flush WCs have seen a significant increase (up from 44\% in 2005 to 54-58\% if intentions are included-in 2015). The other two measures (reuse of white water and rainfed irrigation) involve more complicated investments, requiring structural intervention; it is therefore not surprising that their adoption has been less widespread than that of other practices.

Presently, $87.3 \%$ of hotels only change towels at the request of the client. This result is coherent with the data by the ENEA (the national agency for new technologies, energy, and sustainable economic development) and with a report by the United States EPA (Environmental Protection Agency), which found a reduction in washing machine loads leading to a $17 \%$ decrease in water consumption.

Finally, measures connected with mobility are receiving growing interest from hotels, in line with the data collected in 2005.

\subsection{EMPs and Environmental Commitment: The Identification of Hotels' Profiles}

As already mentioned, the cluster analysis was carried out in order to profile the hotels on the basis of the strength of their environmental commitment. To this end, we decided to analyze the firms' investments in EMPs, noting whether the investments had already been made or were planned. Next, the number of EMPs adopted and planned was calculated, and-for each cluster-the mean of the two values was then calculated. Of the EMPs we investigated, the maximum number of practices that could be adopted was 11-the 10 listed in Table 1 plus the use of organic products in the kitchen. The results of this analysis are given in Table 4.

Table 4. EMPs adopted and planned for each cluster of hotels.

\begin{tabular}{lccc}
\hline & $\begin{array}{c}\text { Mean of EMPs Adopted } \\
\text { (Investments Made) }\end{array}$ & $\begin{array}{c}\text { Mean of EMPs Planned } \\
\text { (Future Investments) }\end{array}$ & $\begin{array}{c}\text { \% of Firms in the } \\
\text { Cluster }(\boldsymbol{n}=\mathbf{1 3 4 7})\end{array}$ \\
\hline CLUSTER 1-Not & 4.1 & 0.4 & $55.3 \%$ \\
eco-friendly & 7.7 & 0.3 & $31.6 \%$ \\
CLUSTER 2-Proactive & 5.2 & 3.0 & $13.1 \%$ \\
CLUSTER 3-Reactive & Source: authors' elaboration.
\end{tabular}

Source: authors' elaboration. 
The first cluster presents a low level of investment in environmental practices and includes all the hotels who, in recent years, have made no, or minimal, investments in the EMPs under investigation, nor do they intend to make any significant future investments in this area. This group makes up 55.3\% of the hotel firms and is identified as the cluster least likely to invest in environmental sustainability. It has thus been labeled "not eco-friendly".

The second cluster has adopted a high number of EMPs (7.7 out of the 11 possible options) but does not intend to make significant further investments. The investments already made by the firms seem to explain the weaker propensity to invest in the near future-precisely because, in fact, of the many EMPs already in place. This group includes approximately one-third of the hotel firms and consists of those hotels who have been quickest to take the opportunities offered by environmentally sustainable investment. We have therefore defined this cluster as "proactive".

The third cluster demonstrates significant interest in future investment in EMPs and covers two tendencies: hotels who have already invested and intend to make further investments and those who have not yet done so but intend to. The latter group comprises $13 \%$ of the hotels, and we describe it as "reactive" since, despite the average of EMPs adopted, its members declare their intention to invest in the near future, thereby reducing the gap between themselves and the proactive hotels.

The definition of "proactive" and "reactive" profiles is inspired by Pereira-Moliner et al. [61]. In their study, the authors identified two different hotel groups. The "proactive" group seems to be particularly aware of the advantages related to EMPs and largely adopts such sustainable practices. On the other hand, the "reactive" group adopts EMPs less compared to the "proactive" one.

The significance of the results obtained by the cluster analysis increases considerably when compared with the findings of the previous (2005) survey. Although a precise comparison of the data cannot be made (because of the methodological differences), the growth in interest in environmental sustainability among hotels over the ten-year period is very evident: in 2005, only $9.1 \%$ of the Trentino hotel firms could have been described as proactive.

In order to identify the distinctive aspects of the three clusters, we then went on to analyze both the motivations that led firms to undertake and/or plan investments in EMPs and the current distribution of environmental certificates and/or labels. Lastly, we investigated whether firms located in areas where the DMO was particularly aware of the issue of sustainability were more likely to fall within the proactive cluster.

\subsection{Motivations for Investing in EMPs and in Environmental Labels}

We analyzed whether the three clusters differed in terms of the motivations prompting hotels to invest in EMPs. These motivations include both advantages related to cost and competitiveness and ethical and cultural dimensions. The hotels' declared levels of agreement with the suggested motivations are compared in Table 5.

The chi-square tests reveal significant differences (with $p$-values always below 0.0001 , except in one case) in the perceptions and opinions of the three clusters with regard to motivations for investments in EMPs, ranging from those rooted in market logic (economic/competitive advantage) to a hotels' individual awareness and concern. Two particularly relevant points emerge:

- The proactive and reactive clusters demonstrate the strongest agreement with the motivations.

- This higher level of agreement is not directly related to market logic, but to ethical reasons ( $49.3 \%$ of the proactive, and $53.1 \%$ of the reactive cluster agrees strongly) and to the importance of maintaining a culture deeply rooted in a symbiosis with the territory (both the proactive and the reactive clusters agree strongly, $48.1 \%$ ). 
Table 5. Level of agreement with the motivations for investment in EMPs, according to cluster.

\begin{tabular}{|c|c|c|c|c|c|c|}
\hline & $\begin{array}{l}\text { Strongly } \\
\text { Agree }\end{array}$ & Agree & Disagree & $\begin{array}{l}\text { Strongly } \\
\text { Disagree }\end{array}$ & Chi-Squared & $p$-Value \\
\hline \multicolumn{5}{|c|}{ APPRECIATED BY CUSTOMERS } & 57.4833 & $<0.0001$ \\
\hline Not Eco-Friendly & $21.0 \%$ & $46.4 \%$ & $27.3 \%$ & $5.4 \%$ & & \\
\hline Proactive & $36.9 \%$ & $44.8 \%$ & $17.4 \%$ & $0.9 \%$ & & \\
\hline Reactive & $35.6 \%$ & $40.7 \%$ & $21.5 \%$ & $2.3 \%$ & & \\
\hline \multicolumn{5}{|c|}{ ENABLE COST SAVINGS } & 24.9060 & 0.0004 \\
\hline Not Eco-Friendly & $25.7 \%$ & $51.1 \%$ & $18.7 \%$ & $4.6 \%$ & & \\
\hline Proactive & $33.8 \%$ & $46.7 \%$ & $18.1 \%$ & $1.4 \%$ & & \\
\hline Reactive & $26.6 \%$ & $57.1 \%$ & $16.4 \%$ & $0.0 \%$ & & \\
\hline \multicolumn{5}{|c|}{ CAN GIVE COMPETITIVE ADVANTAGE } & 39.6892 & $<0.0001$ \\
\hline Not Eco-Friendly & $15.7 \%$ & $42.5 \%$ & $33.1 \%$ & $8.7 \%$ & & \\
\hline Proactive & $25.8 \%$ & $43.4 \%$ & $27.2 \%$ & $3.5 \%$ & & \\
\hline Reactive & $27.7 \%$ & $43.5 \%$ & $26.6 \%$ & $2.3 \%$ & & \\
\hline \multicolumn{5}{|c|}{ PROBABLY UNAVOIDABLE IN ORDER TO REMAIN IN THE MARKET } & 34.1991 & $<0.0001$ \\
\hline Not Eco-Friendly & $11.2 \%$ & $40.5 \%$ & $37.5 \%$ & $10.9 \%$ & & \\
\hline Proactive & $17.8 \%$ & $46.7 \%$ & $30.1 \%$ & $5.4 \%$ & & \\
\hline Reactive & $14.1 \%$ & $52.0 \%$ & $29.9 \%$ & $4.0 \%$ & & \\
\hline \multicolumn{5}{|c|}{ STRONG PERSONAL ETHICAL MOTIVATION } & 75.0996 & $<0.0001$ \\
\hline Not Eco-Friendly & $30.0 \%$ & $50.9 \%$ & $14.3 \%$ & $4.8 \%$ & & \\
\hline Proactive & $49.3 \%$ & $43.2 \%$ & $6.3 \%$ & $1.2 \%$ & & \\
\hline Reactive & $53.1 \%$ & $39.0 \%$ & $6.8 \%$ & $1.1 \%$ & & \\
\hline \multicolumn{5}{|c|}{$\begin{array}{l}\text { IMPORTANT IN TRENTINO, FOR MAINTAINING THE CULTURE, } \\
\text { WHICH IS CLOSELY LINKED TO THE TERRITORY }\end{array}$} & 69.5510 & $<0.0001$ \\
\hline Not Eco-Friendly & $29.0 \%$ & $51.5 \%$ & $15.2 \%$ & $4.3 \%$ & & \\
\hline Proactive & $48.1 \%$ & $41.1 \%$ & $10.6 \%$ & $0.2 \%$ & & \\
\hline Reactive & $48.0 \%$ & $45.2 \%$ & $5.1 \%$ & $1.7 \%$ & & \\
\hline
\end{tabular}

Source: authors' elaboration.

This analysis reveals some of the factors that distinguish the three clusters.

The reactive cluster is characterized by ethical motivations that indicate that these hotels are generally aware of the importance of environmental sustainability and are probably willing to close the gap with the proactive cluster by investing in EMPs in the near future.

The non-eco-friendly cluster, on the other hand, appears to be less enthusiastic about investing in EMPs than the other two groups. Hotels in this cluster are dubious as to whether sustainability provides any competitive advantage, is appreciated by customers, or could be a key to remain in the market.

Environmental labels and quality management and/or environmental management certificates still prove to have limited reach. A preliminary descriptive comparative analysis of the two surveys reveals that the percentage of hotels with certification has increased from $4.8 \%$ (in 2005) to $10.8 \%$ in 2015; few firms have invested in any kind of certification scheme, notwithstanding the fact that, on the one hand, interest in environmental issues in general has increased and, on the other hand, public policy since 2010 has been to incentivize applications for environmental labels.

Our multivariate analysis of the data reveals a significant statistical difference between the clusters (chi-squared 117.4609; $p$-value < 0.0001), both with regard to current certification and plans to apply for it in the future, as Table 6 illustrates. 
Table 6. Prevalence of certification (current and future) in the three clusters.

\begin{tabular}{lccc}
\hline & $\begin{array}{c}\text { \% of Hotels with } \\
\text { Certification }\end{array}$ & $\begin{array}{c}\text { \% of Hotels in the Process } \\
\text { of Gaining Certification }\end{array}$ & $\begin{array}{c}\text { \% of Hotels without } \\
\text { Certification }\end{array}$ \\
\hline Not Eco-Friendly & $5.0 \%$ & $2.2 \%$ & $92.8 \%$ \\
Proactive & $19.3 \%$ & $6.8 \%$ & $73.9 \%$ \\
Reactive & $14.1 \%$ & $4.5 \%$ & $81.4 \%$ \\
\hline
\end{tabular}

Source: authors' elaboration.

\subsection{Links between the Adoption of EMPs and Collaboration with Local Players}

The research investigated possible differences between the three clusters in terms of collaboration with the local DMOs and other hotels in the development and promotion of the territory. Our findings show that hotels in the proactive cluster collaborate most actively with the DMO (and this to a statistically significant extent) (see Table 7), and the level of collaboration is higher (see Figure 2). Here, too, the difference between the three clusters is statistically significant (chi-squared 32.397; $p$-value $<0.0001$ ), and particularly marked between the non-eco-friendly cluster and proactive cluster. Moreover, a greater similarity is revealed between the reactive cluster and the proactive cluster, in line with the previously discussed analysis of motivations for investment in EMPs: the trend within the former to reduce the gap that separates it from the latter.

Table 7. Analysis of the three clusters' links within the territory.

\begin{tabular}{lcccc}
\hline & Yes & No & Chi-Squared & $p$-Value \\
\hline COLLABORATION WITH THE DMO & & & 29.606 & $<0.0001$ \\
Not eco-friendly & $62.6 \%$ & $37.4 \%$ & & \\
Proactive & $77.9 \%$ & $22.1 \%$ & & \\
Reactive & $70.1 \%$ & $29.4 \%$ & & $<0.0001$ \\
\hline COLLABORATION WITH OTHER HOTELIERS & & & 45.337 & \\
Not eco-friendly & $19.9 \%$ & $80.1 \%$ & & \\
Proactive & $36.4 \%$ & $63.6 \%$ & & \\
Reactive & $36.2 \%$ & $63.8 \%$ & & \\
\hline
\end{tabular}

Source: authors' elaboration.

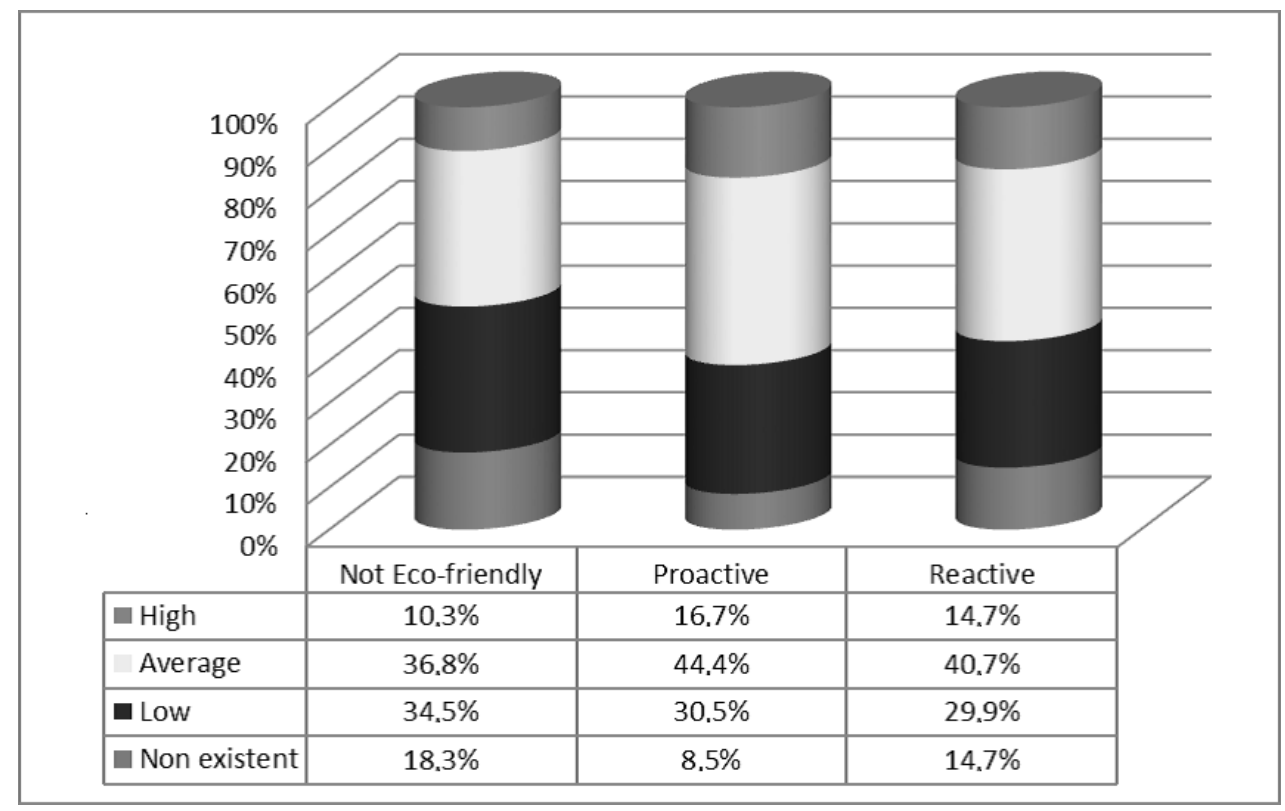

Figure 2. Analysis of the levels of collaboration between the three clusters and their local DMOs. 
The analysis of collaboration between hotels and DMOs thus revealed a link between the proactive cluster and the reactive cluster and the influence that the key players have on the choices they make with regard to investing in EMPs: the influence of the DMO emerged as a determining factor for the proactivity of the hotels in these clusters. Collaboration among hotels is also significant in spite of data showing a lower percentage (Table 7). The difference between proactive and reactive hotels and not eco-friendly hotels remains significant.

Another level of analysis considered the locations of the hotels in the proactive cluster within the various tourist areas of Trentino in order to establish whether or not there is a connection between their environmental commitment and the tourism intensity related to the net occupancy rate of hotels (Table 8).

Table 8. Analysis of tourist areas in terms of the presence of pro-active firms.

\begin{tabular}{lccc}
\hline \multicolumn{1}{c}{ Trentino Tourist Area } & $\begin{array}{c}\text { Number of Visitor } \\
\text { Overnight Stays } \\
\text { (Hotels only) }\end{array}$ & $\begin{array}{c}\text { Net Occupancy } \\
\text { Rate }\end{array}$ & $\begin{array}{c}\text { \% Firms in } \\
\text { the Proactive } \\
\text { Cluster }\end{array}$ \\
\hline Trentino Garda Lake & $1,889,302$ & $63.0 \%$ & $29.4 \%$ \\
Val di Fassa & $2,271,306$ & $60.4 \%$ & $32.6 \%$ \\
Val di Sole & $1,570,256$ & $59.1 \%$ & $32.3 \%$ \\
Val di Fiemme & 906,518 & $55.7 \%$ & $44.9 \%$ \\
Madonna di Campiglio-Pinzolo-Rendena & 999,145 & $51.7 \%$ & $27.4 \%$ \\
Trento, Bondone e Valle dei Laghi & 524,902 & $48.6 \%$ & $32.7 \%$ \\
Altipiani Cimbri & 468,124 & $46.3 \%$ & $35.0 \%$ \\
Primiero e Vanoi & 585,447 & $42.8 \%$ & $32.1 \%$ \\
Dolomiti Brenta-Paganella & $1,108,492$ & $39.7 \%$ & $38.2 \%$ \\
Rovereto & 225,996 & $36.2 \%$ & $20.6 \%$ \\
Terme di Comano-Brenta & 159,472 & $34.7 \%$ & $32.1 \%$ \\
Valsugana-Tesino & 476,463 & $31.0 \%$ & $25.3 \%$ \\
Valle di Non & 239,788 & $30.3 \%$ & $29.6 \%$ \\
Altopiano di Piné-Cembra & 114,791 & $25.0 \%$ & $25.0 \%$ \\
Off the Beaten Track Zones * & 244,788 & $23.5 \%$ & $22.6 \%$ \\
\hline Total & $11,784,790$ & $48.8 \%$ & $31.6 \%$ \\
\hline
\end{tabular}

Note: * have no DMO; Source: authors' elaboration.

Table 8 shows that the more touristic areas are not necessarily home to the more proactive firms. The Trentino Lake Garda and the Valle di Fiemme best exemplify this fact: the net occupancy rate of Trentino Lake Garda is $63.0 \%$ vs. $29.4 \%$ of proactive hotels; the net occupancy rate of Valle di Fiemme is $55.7 \%$ vs. $44.9 \%$ of proactive hotels. Further evidence emerged from the so-called "off the beaten track zones," i.e., the less touristic areas without an official DMO. Here, only $22.6 \%$ of the hotels are proactive (as against the provincial average of 31.6\%); furthermore (although not evidenced by Table 8), these areas also contain a lower percentage of reactive firms: $7.1 \%$ vs. the province's $13.1 \%$. The absence of the guiding hand of a DMO is a factor common to all the "off the beaten track zones," which are, instead, shaped by smaller bodies with little capacity to enhance or manage effectively.

\section{Discussion and Conclusions}

This study revealed new and original aspects of the propensities of hotels to invest in EMPs. From 2005 to 2015, investments by hotels in EMPs increased, particularly referring to measures such as energy and water conservation. The research-for the first time in Italy-identified three different environmental hotels profiles: proactive, reactive, and not eco-friendly. The research investigated both types of EMPs adopted by small hotels and the link between hotels' environmental commitment and the collaboration with key stakeholders. The cluster analysis demonstrated that the proactive and reactive hotels have a greater propensity to collaborate both with the DMO and with other local hotels.

From a theoretical point of view, the research helped to reduce the knowledge gap on the adoption of EMPs by small hotels highlighted in the literature. As underlined, the focus of past research 
was on choices and strategies followed by big hotels and/or hotel chains characterized by greater resources and able to exploit economies of scale [44-47]. Small hotels have fewer resources and have to follow other strategies to reach competitiveness such as, first of all, collaboration with local actors. Our research showed that the scant attention paid by small hotels to investment in the environment is due not only to individual hotels' lack of awareness but also to the lack of collaboration with other key actors involved in the tourism chain. An original result of our research underlined the increase of proactive and reactive hotels investing in EMPs explained by (a) their greater awareness of environmental sustainability and the ethical value that they place on it, and (b) the influence of the DMO to support collaboration among actors. Our research showed the existence of a relation between the adoption of EMPs and the stakeholder power and/or stakeholder pressure exerted by key local actors.

Proactive hotels are more consistent with tourist areas not involved in mass tourism. The three areas in which this profile is more evident are territories where tourism is vital for the development of the entire area, and the DMOs promote tourism with particular attention on sustainability. This decision can be considered coherent with the adoption of a new business model capable of producing competitive advantage both for the firm itself and for the area in which it is located, resulting in, as highlighted by [49,50], a "win-win for firm and system."

From a managerial point of view, it is assumed that imitative behaviors in the adoption of EMPs are likely to take place in community destinations. Mainly the proactive profile, along with the reactive one, could be considered "first movers" and imitated by (at least from a part of) the non-eco-friendly hotels. The increased investments in EMPs since 2005 showed hotels' awareness of the importance of sustainability practices to manage the enterprises and the opportunities offered by their adoption to reach differentiation strategy goals. This last consideration is also emphasized in light of the current trends evidencing demand segments interested in sustainable tourism offer and particularly aware on green practices adopted by hotels [62]. The adoption of EMPs by hotels could therefore contribute to destination competitiveness. For this reason, our research findings could be a stimulus (a) for hotels to promote their strategy and their attention to EMPs and to strengthen collaborative relationships with key players and local actors and (b) for policy makers to recommend and support (also through public incentives and subsidies) the adoption of EMPs to the accommodation sector as a whole (not only hotels) and to other key players of the territory.

These last issues, however, to be confirmed need to be investigated in further research. Having been conducted in one community destination only, the extent to which this study of the Trentino hotels can be extended to other territories is, of course, limited. We therefore intend to widen it in the future, across other territories and sectors and longitudinally.

Further research would also involve investigating the choices made by hotel firms in other destinations, analyzing whether the three profiles which emerged from this study are coherent with behavior patterns in other destinations, and which—if any-key players facilitate firms' adoption of EMPs.

Future research could also usefully extend the analysis to other firms involved in the tourism chain, such as cable car companies. Here, the objective would be to examine whether or not the environmental awareness observed among hotels is shared by other key players whose activities inevitably have environmental impacts and thereby risk compromising the very resource which is so crucial to the destination's competitiveness.

Finally, with regard to the temporal aspect-the intention is to replicate the longitudinal analysis carried out in 2015 in Trentino, in order to investigate whether and how the three profiles change between 2015 and 2025 and what impact EMPs have on a hotel's performance.

Author Contributions: Conceptualization, F.B., M.F. and U.M.; Data curation, A.T.; Formal analysis, A.T.; Funding acquisition, M.F.; Investigation, A.T.; Methodology, F.B. and M.F.; Project administration, M.F.; Supervision, M.F. and U.M.; Visualization, A.T.; Writing—original draft, F.B. and A.T.; Writing—review \& editing, F.B., M.F. and U.M. 
Funding: This research was co-funded by Univeristy of Trento and the Statistical Office of Province of Trento (ISPAT) grant number [40102858] And The APC was funded by Department of Economics and Management of the University of Trento (Italy).

Acknowledgments: This work was developed within the research project "Analisi dell'imprenditoria alberghiera della Provincia di Trento", which was financed by the Statistical Office of Province of Trento (ISPAT) and the Department of Economics and Management of the University of Trento (Italy). ISPAT is here acknowledged for providing access to the data.

Conflicts of Interest: The authors declare no conflict of interest.

\section{References}

1. Inskeep, E. Tourism Planning: An Integrated and Sustainable Development Approach; Van Nostrand Reinhold: New York, NY, USA, 1991; ISBN 047129392X.

2. Swarbrooke, J. Sustainable Tourism Management; CABI: Wallingford, UK, 1999; ISBN 0851993141.

3. Font, X.; Mccabe, S. Sustainability and marketing in tourism. J. Sustain. Tour. 2017, 25, 869-883. [CrossRef]

4. Bramwell, B.; Lane, B. Sustainable tourism: An evolving global approach. J. Sustain. Tour. 1993, 1, 1-5. [CrossRef]

5. McKercher, B. Some Fundamental Truths about Tourism. J. Sustain. Tour. 1993, 1, 6-16. [CrossRef]

6. Butler, R.W. Sustainable Tourism: A state-of-the-art review. Tour. Geogr. 1999, 1, 7-25. [CrossRef]

7. Chen, J.S.; Johnson, C.; Wang, W.; Chen, Y.-L. Stakeholders' Perspective of Sustainability in an Arctic Region: A Qualitative Study. Tour. Anal. 2014, 19, 85-96. [CrossRef]

8. Hardy, A.; Beeton, R.J.S.; Pearson, L. Sustainable tourism: An overview of the concept and its position in relation to conceptualisations of tourism. J. Sustain. Tour. 2002, 10, 475-496. [CrossRef]

9. Hunter, C. Sustainable tourism as an adaptive paradigm. Ann. Tour. Res. 1997, 24, 850-867. [CrossRef]

10. Okech, R.N. Ecotourism Development and Challenges: A Kenyan Experience. Tour. Anal. 2011, 16, 19-30. [CrossRef]

11. Ryan, C. Equity, management, power sharing and sustainability. Issues of the 'new tourism'. Tour. Manag. 2002, 23, 17-26. [CrossRef]

12. Buhalis, D.; Main, H. Information technology in peripheral small and medium hospitality enterprises. Int. J. Contemp. Hosp. Manag. 1998, 10, 198-202. [CrossRef]

13. Keller, P.; Bieger, T. The Future of Small and Medium Sized Enterprises in Tourism; Editions AIEST: St. Gallen, Switzerland, 2004; ISBN 3952172359.

14. Kozak, M.; Rimmington, M. Benchmarking: Destination attractiveness and small hospitality business performance. Int. J. Contemp. Hosp. Manag. 1998, 10, 184-191. [CrossRef]

15. Blanco, E.; Rey-Maquieira, J.; Lozano, J. Economic incentives for tourism firms to undertake voluntary environmental management. Tour. Manag. 2009, 30, 112-122. [CrossRef]

16. El Dief, M.; Font, X. Determinants of Environmental Management in the Red Sea hotels. J. Hosp. Tour. Res. 2010, 36, 115-137. [CrossRef]

17. Beeton, S. Community Development through Tourism, 1st ed.; Landlinks Press: Collingwood, UK, 2006; ISBN 9780643093881.

18. Kaspar, C. Management im Tourismus; Verlag Paul Haupt.: Bern, Switzerland, 1995.

19. Murphy, P.E. Tourism: A Community Approach; Methuen: New York, NY, USA, 1985; ISBN 9780415626156.

20. Murphy, P.E.; Murphy, A.E. Strategic Management for Tourism Communities: Bridging the Gaps; Channel View Books: Clevedon, UK, 2004; ISBN 1873150830.

21. Dwyer, L.; Edwards, D.; Mistilis, N.; Roman, C.; Scott, N. Destination and enterprise management for a tourism future. Tour. Manag. 2009, 30, 63-74. [CrossRef]

22. Gössling, S.; Hall, C.M.; Weaver, D.B. Sustainable Tourism Futures, 1st ed.; Routledge: London, UK, 2009; ISBN 9781135843243.

23. Weaver, D.B. Organic, incremental and induced paths to sustainable mass tourism convergence. Tour. Manag. 2011, 30, 1-8. [CrossRef]

24. Crouch, G.I. Modelling Destination Competitiveness: A Survey and Analysis of the Impact of Competitiveness; Report of the Cooperative Research Centre for Sustainable Tourism; Sustainable Tourism CRC: Gold Coast, Australia, 2007. 
25. Mazanec, J.A.; Woeber, K.; Zins, A.H. Tourism destination competitiveness: From definition to explanation? J. Travel Res. 2007, 46, 86-95. [CrossRef]

26. Middleton, V.T.C.; Hawkins, R. Sustainable Tourism: A Marketing Perspective; Butterworth-Heinemann: Oxford, UK, 1998; ISBN 0750623853.

27. Mihalic, T. Environmental management of a tourist destination. A factor of tourism competitiveness. Tour. Manag. 2000, 21, 65-78. [CrossRef]

28. Ritchie, J.R.B.; Crouch, G.I. The Competitive Destination: A Sustainable Tourism Perspective, 1st ed.; CABI: Oxon, UK, 2003; ISBN 0851996647.

29. Bramwell, B.; Lane, B. Tourism Collaboration and Partnerships: Politics, Practice and Sustainability, 1st ed.; Channel View Publications: Clevedon, UK, 2000; ISBN 1873150792.

30. Hall, C.M. Tourism and Politics: Policy, Power and Place, 1st ed.; John Wiley: Chichester, UK, 1994; ISBN 9780471965473.

31. Hall, C.M. Rethinking collaboration and partnership: A public policy perspective. J. Sustain. Tour. 1999, 7, 274-289. [CrossRef]

32. Hall, C.M. A typology of governance and its implications for tourism policy analysis. J. Sustain. Tour. 2011, 19, 437-457. [CrossRef]

33. Hall, C.M.; Jenkins, J.M. Tourism and Public Policy; Routledge: London, UK, 1995; ISBN 1861529988.

34. Bumyong, A.; Bongkoo, L.; Scott Shafer, C. Operationalizing sustainability in regional tourism planning: An application of the limits of acceptable change framework. Tour. Manag. 2002, 23, 1-15.

35. Hjalager, A.M. Tourism and the environment: The innovation connection. J. Sustain. Tour. 1996, 4, $201-218$. [CrossRef]

36. Hunter, C.; Green, H. Tourism and Environment: A Sustainable Relationship? Routledge: London, UK, 1995; ISBN 9780415085243.

37. Bramwell, B.; Lane, B. Critical research on the governance of tourism and sustainability. J. Sustain. Tour. 2011, 19, 411-421. [CrossRef]

38. Ritchie, J.R.B.; Crouch, G.I. Editorial-The competitive destination: A sustainability perspective. Tour. Manag. 2000, 21, 1-7. [CrossRef]

39. Rizio, D. A Multicriteria Perspective to Integrate Environmental Management and Environmental Accounting in the Tourism Industry. The Case of Small and Medium-sized Hotel Enterprises (SMHEs) in the Alpine Province of Trento. Ph.D. Thesis, University of Trento, Trento, Italy, 2016.

40. Gössling, S.; Peeters, P.; Hall, C.M.; Ceron, J.P.; Dubois, G.; Lehmann, L.V.; Scott, D. Tourism and water use: Supply, demand, and security. An international review. Tour. Manag. 2012, 33, 11-15. [CrossRef]

41. Bohdanowicz, P. European hoteliers' environmental attitudes. Greening the Business. Cornell Hotel Restaur. Adm. Q. 2005, 46, 188-204. [CrossRef]

42. Kirk, D. Environmental management in hotels. Int. J. Contemp. Hosp. Manag. 1995, 7, 3-8. [CrossRef]

43. Chan, E.S.W.; Hawkins, R. Attitude towards EMSs in an international hotel. Int. J. Contemp. Hosp. Manag. 2010, 29, 641-651. [CrossRef]

44. Álvarez-Gil, M.J.; Burgos Jiménez, J.; Céspedes Lorente, J.J. An analysis of environmental management, organizational context and performance of Spanish hotels. Omega 2001, 29, 457-471. [CrossRef]

45. López-Gamero, M.D.; Molina-Azorín, J.F.; Claver-Cortés, E. The whole relationship between environmental variables and firm performance. J. Environ. Manag. 2009, 90, 3110-3121. [CrossRef]

46. Molina-Azorín, J.F.; Claver-Cortés, E.; Pereira-Moliner, J.; Tarí, J.J. Environmental practices and firm performance. J. Clean. Prod. 2009, 17, 516-524. [CrossRef]

47. Enz, C.A.; Siguaw, J.A. Best Hotel Environmental Practices. Cornell Hotel Restaur. Adm. Q. 1999, 40, $72-77$. [CrossRef]

48. Buffa, F.; Franch, M.; Rizio, D. Environmental management practices for sustainable business models in small and medium sized hotel enterprises. J. Clean. Prod. 2018, 194, 656-664. [CrossRef]

49. Porter, M.E.; Kramer, M.R. Creating Shared Value. Harv. Bus. Rev. 2011, 89, 62-77.

50. Boons, F.; Lüdeke-Freund, F. Business models for sustainable innovation. J. Clean. Prod. 2013, 45, 9-19. [CrossRef]

51. Tarí, Y.H.; Claver-Cortés, E.; Pereira-Moliner, J.; Molina-Azorín, J.F. Levels of quality and environmental management in the hotel industry. Int. J. Hosp. Manag. 2010, 29, 500-510. [CrossRef] 
52. Fraj, E.; Matute, J.; Melero, I. Environmental strategies and organizational competitiveness in the hotel industry. Tour. Manag. 2015, 46, 30-42. [CrossRef]

53. Kassinis, G.I.; Soteriou, A.C. Greening the service profit chain: The impact of environmental management practices. Prod. Oper. Manag. 2003, 12, 386-403. [CrossRef]

54. Sánchez-Medina, P.S.; Díaz-Pichardo, R.; Cruz-Bautista, M. Stakeholder Influence on the Implementation of Environmental Management Practices in the Hotel Industry. Int. J. Tour. Res. 2016, 18, 387-398. [CrossRef]

55. Céspedes-Lorente, J.; De Burgos-Jiménez, J.; Álvarez-Gil, M. Stakeholders' environmental influence. An empirical analysis in the Spanish hotel industry. Scand. J. Manag. 2003, 19, 333-358. [CrossRef]

56. Ayuso, S. Adoption of Voluntary Environmental Tools for sustainable tourism. Corp. Soc. Responsib. Environ. Manag. 2006, 13, 207-220. [CrossRef]

57. González-Benito, J.; González-Benito, Ó. A review of determinant factors of environmental proactivity. Bus. Strategy Environ. 2006, 15, 87-102. [CrossRef]

58. Tang, Y.H.; Amran, A.; Goh, Y.N. Environmental management practices of hotels in Malaysia. Int. J. Tour. Res. 2014, 16, 586-595. [CrossRef]

59. ISTAT. Annuario Statistico Italiano 2017; ISTAT: Roma, Italy, 2017.

60. ISPAT (Statistical Office of Province of Trento). L'imprenditoria Alberghiera Nella Provincia di Trento 2004; Servizio Statistica: Trento, Italy, 2006.

61. Pereira-Moliner, J.; Font, X.; Tarì, J.J.; Molina-Azorin, J.F.; Lopez-Gamero, M.D.; Pertusa-Ortega, E.M. The Holy Grail: Environmental management, competitive advantage and business performance in the Spanish hotel industry. Int. J. Contemp. Hosp. Manag. 2015, 27, 714-738. [CrossRef]

62. Chen, Y.L. Hotel Guest's Green Lodging Experiences: A Segmentation Study. In Advances in Hospitality and Leisure; Chen, J.S., Ed.; Emerald Publishing Limited: Bingley, UK, 2017; Volume 13, pp. 127-139, ISBN 978-1-78743-488-2. 